\title{
Kinking of Flow Diverter in a Giant Wide-Necked Supraclinoid Internal Carotid Artery Aneurysm
}

\author{
Soumik Das, MD, Arun Kumar Gupta, MD, Arvinda Hanumathapura Ramalingiah, MD
}

We report here a rare complication in the form of kinking of flow diverter in a case of giant widenecked supraclinoid internal carotid artery (ICA) aneurysm 48 hours after the procedure. This 28-year female presented with giant wide-necked right supraclinoid ICA aneurysm which was managed by flow diversion. On 2nd post-op day, patient developed weakness of left side with altered sensorium - angiography and CT showed kinking of flow diverter at the neck of the aneurysm with poor distal flow. Eventually, the patient developed right middle cerebral artery infarct for which decompressive hemicraniectomy was done. The likely cause of development of kink is because the aneurysm was widenecked, the hemodynamic forces have resulted in inward buckling of the flow diverter at the aneurysm neck. This case shows that kinking of flow diverter can still happen 48 hours post-procedure.

Key Words : Kinking; Flow diverter; Giant aneurysm

Flow diversion is a well-established endovascular technique for the management of giant supraclinoid internal carotid artery (ICA) aneurysms. We report here kinking of the flow diverter in a case of giant right supraclinoid ICA aneurysm which was managed by flow diversion. The patient subsequently developed right middle cerebral artery (MCA) infarct for which decompressive hemicraniectomy was done. The possible mechanism of kinking is discussed and preventive measures are suggested. This case shows that kinking of flow diverter can happen even 48 hours

All authors: Department of Neuroimaging and Interventional Radiology, NIMHANS, Bangalore - 29, India

Received December 29, 2017; Revised January 20, 2018;

Accepted January 20, 2018

Correspondence to: Arun Kumar Gupta, MD

Department of Neuroimaging and Interventional Radiology, Third Floor, Faculty Block, NIMHANS, Hosur Road, Bangalore - 560029, India

E-mail: gupta209@gmail.com

This is an Open Access article distributed under the terms of the Creative Commons Attribution Non-Commercial License (http://creativecommons.org/licenses/by-nc/3.0) which permits unrestricted non-commercial use, distribution, and reproduction in any medium, provided the original work is properly cited. after procedure.

\section{CASE REPORT}

This 28-year female presented with four months' history of headache and vomiting. To rule out intracranial pathology magnetic resonance imaging (MRI) was advised which showed giant right supraclinoid ICA aneurysm measuring $4.3 \times 4.2 \mathrm{~cm}$ approximately with hydrocephalous. Left ventriculo-peritoneal shunt was done in a referring hospital and the patient was referred to us. Digital subtraction angiography (DSA) confirmed the presence of giant wide-necked supraclinoid ICA aneurysm. Considering the size and feasibility, flow diverter placement was planned. The patient was loaded with $40 \mathrm{mg}$ of prasugrel night before procedure.

Informed consent was taken. Through the right femoral route using 7Fr long sheath, Headway 27 microcatheter (MicroVention, Inc., Tustin, CA, USA) was taken over Traxcess 14 microguidewire (MicroVention, Inc) and navigated distally into right MCA. Two long coils $(15-20-\mathrm{mm} \times 60 \mathrm{~cm} \mathrm{VFC}$ 


\section{Kinking of Flow Diverter in a Wide-Necked Aneurysm}

MicroPlex) (Micro Vention, Inc) were deployed into aneurysmal sac. FRED flow diverter (MicroVention, Inc) $(4 \times 44 \mathrm{~mm})$ was deployed across aneurysm neck from the M1 segment of right MCA to the distal cavernous ICA on the right side. Check injection showed patency of FRED with slowing of circulation in the aneurysm sac (Fig. 1). Intravenous infusion of Tirofiban was given at $0.4 \mu \mathrm{g} / \mathrm{kg} / \mathrm{min}$ for 30 minutes followed by $0.1 \mu \mathrm{g} / \mathrm{kg} / \mathrm{min}$ for 18 hours.

On 2nd post-op day (48 hours post-procedure)Patient developed weakness of left side with altered sensorium and was immediately shifted to DSA which showed kinking of flow diverter at the neck of the aneurysm with poor distal flow (Fig. 2). It was planned to perform balloon angioplasty at the site of the kink. It was attempted to manipulate a microcatheter and microguidewire distal to the kink; however, it was not possible to negotiate even the microguidewire through the kinked flow diverter. Antiplatelet was continued and patient was kept on observation.

On 5th post-op day - Patient worsened in sensorium (E1M3VT) and MRI done showed multifocal infarcts in right MCA territory. At this stage, anti-platelet medications were discontinued seeing the risk of hemorrhagic transformation of infarct and was taken for emergency decompressive hemicraniectomy. She improved to M4 status with persisting pupillary asymmetry and left sided paucity of movements. Subsequent CT scans revealed right MCA infarct. The neurological status at discharge is E4M3. The patient has shown gradual improvement over time and at present, has a modified Rankin score of 4.

\section{DISCUSSION}

Since the advent of flow diverters such as Silk (Balt
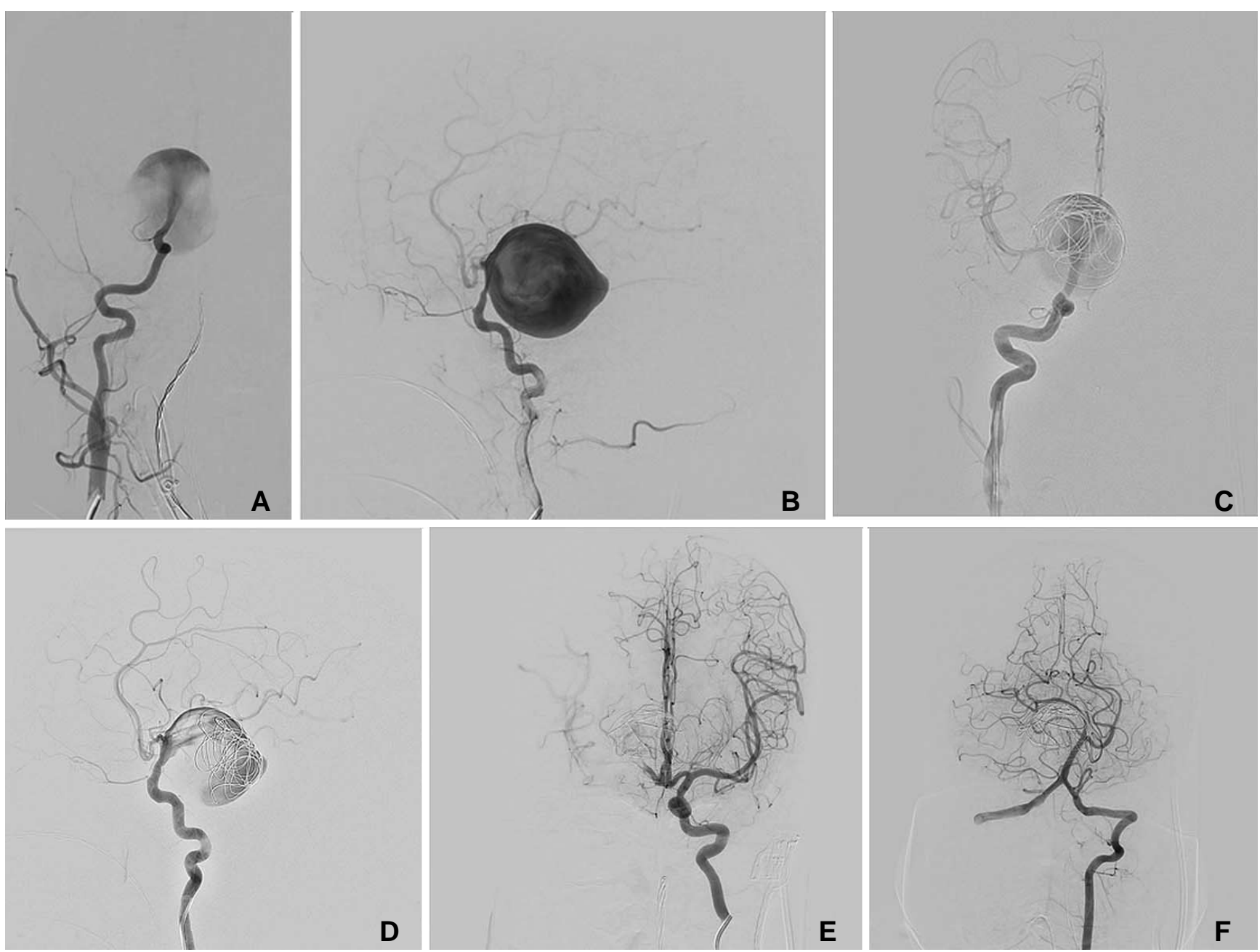

Fig. 1. (A, B) Right internal carotid angiogram both AP and lateral views show giant right supraclinoid internal carotid artery (ICA) aneurysm. (C, D) Embolization with coil and deployment of FRED done. Subsequent angiogram showed patency of FRED with slowing of circulation in the aneurysm sac. (E, F) Post-procedure left internal carotid and left vertebral artery angiogram revealed opacification of all intracranial vessels. 

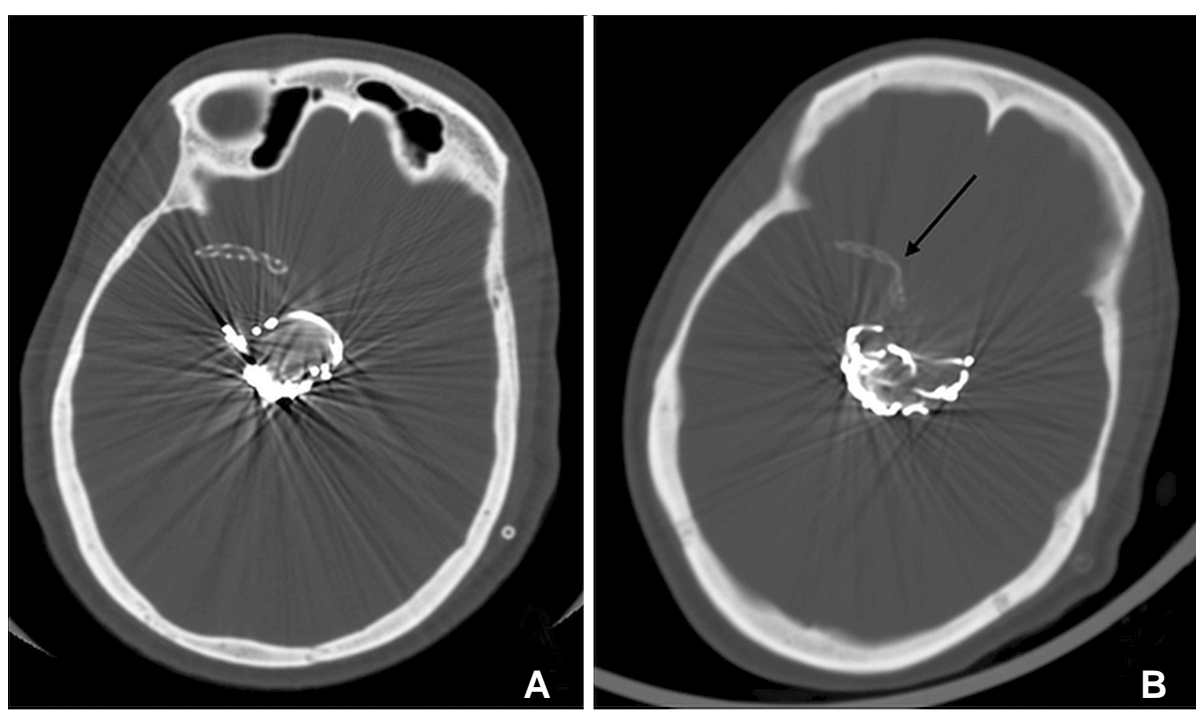

Fig. 2. (A) Immediate post-procedure check CT shows complete opening of flow diverter. (B) CT scan done 48 hours post-procedure for evaluation of neurological deterioration shows kinking of flow diverter (black arrow). (C, D) Right internal carotid angiogram on 2nd post-op day showed kinking of flow diverter at the neck of the aneurysm with poor distal flow. (E) CT scan showing right MCA infarct with kinked flow diverter (black arrow) for which decompressive hemicraniectomy was done.
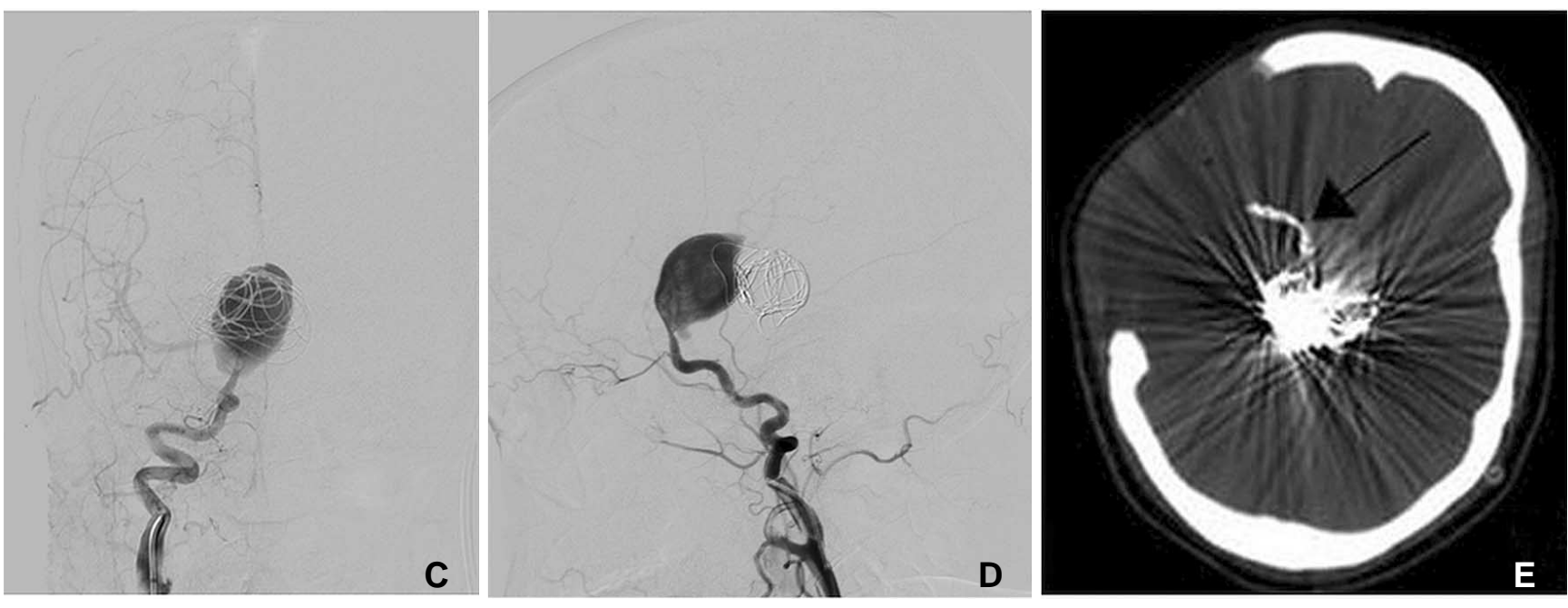

Extrusion, Montmorency, France) and (Pipeline Embolization Device) PEDs (ev3/Covidien, Irvine, CA, USA), the treatment of giant aneurysm has changed rapidly. Flow-diverting devices represent a significant advancement in endovascular remodelling strategies of aneurysm treatment.

The mechanism of action of flow diverters is based on two concepts: firstly, by disruption of blood flow from parent artery into the aneurysm, and secondly, by providing a scaffold for endothelial cells to grow thereby isolating the aneurysm from parent artery. ${ }^{2}$ Following deployment of flow diverter, the aneurysm gradually begins to thrombose, and eventually shrinks and collapses around the device construct. ${ }^{3}$ Over a period of 6-12 months, as endothelialisation gradually progresses and aneurysmal thrombosis continues, parent vessel is reconstructed with aneurysmal occlusion and resorption of the thrombus. ${ }^{4-6}$

The metallic surface area coverage of flow diverters is approximately $30-50 \%$ of the total surface area of the aneurysm neck and the porosity is $60-76 \%$ as compared with $89 \%$ porosity in stents used in stentassisted coiling. This optimal balance between porosity and pore density allows preservation of perforators and small branches, while achieving aneurysmal thrombosis, reduction in rupture risk and recanalization rates of treated aneurysms.

The FRED flow diverter is a closed-cell, paired-stent flow diversion device and is currently CE-Marked in Europe. FRED has a unique integrated dual-layer (stent-within-a-stent) design with an outer, highporosity stent composed of 16 nitinol wires and an inner, low-porosity, flow-diverting mesh composed of 48 braided nitinol strands. This integrated dual-layer coverage offers enhanced radial force with the 48-wire inner stent layer providing $22 \%$ to $44 \%$ metal coverage. If the device is not correctly positioned across the aneurysm neck, the pusher allows resheathing and 
repositioning of the stent as long as $\leq 80 \%$ of its length has been unsheathed/deployed.

In a study conducted by Diaz et al. ${ }^{7}$, the FRED system was technically easy to deploy with no procedural complications occurring in this first reported series of 14 aneurysms. The ability of the FRED system to be recaptured after partial deployment and to maintain its internal shape in tortuous vessels was well demonstrated.

In our case, FRED flow diverter $(4 \times 44 \mathrm{~mm})$ was deployed across aneurysm neck from the M1 segment of MCA to the distal cavernous ICA on the right side. Before the placement of flow diverter, few long coils were deployed to augment thrombosis of the aneurysm. Subsequent angiogram showed patency of FRED with slowing of circulation in the aneurysm sac. We could observe filling of all the branches of the right ICA on post-procedure angiogram. Tirofiban infusion was continued for 18 hours post-procedure to minimise the risk of thrombo-embolic complications. The patient was neurologically intact for 48 hours after the procedure. On the 2 nd post-op day, patient developed weakness of left side with altered sensorium and was immediately shifted to DSA which showed kinking of flow diverter at the neck of the aneurysm with poor distal flow.

The likely cause of development of kink is because the aneurysm was wide-necked, the hemodynamic forces have resulted in inward buckling of the flow diverter at the aneurysm neck. It could have been prevented by: packing the aneurysm with more coils thereby providing a scaffold against which the flow diverter would be supported or by deploying a longer length braided stent like LEO (Balt Extrusion,
Montmorency, France) or LVIS (MicroVention, Inc) initially and then deploying the flow diverter within it. ${ }^{8}$ Eventually, our patient developed right MCA infarct for which decompressive hemicraniectomy was done. In summary, this case shows that kinking of flow diverter can occur 48 hours post-procedure.

\section{References}

1. Fiorella D, Woo HH, Albuquerque FC, Nelson PK. Definitive reconstruction of circumferential, fusiform intracranial aneurysms with the pipeline embolization device. Neurosurgery 2008;62: $1115-1120$

2. Krishna C, Sonig A, Natarajan SK, Siddiqui AH. The expanding realm of endovascular neurosurgery: flow diversion for cerebral aneurysm management. Methodist Debakey Cardiovasc J 2014; 10:214-219

3. Becske T, Kallmes DF, Saatci I, McDougll CG, Szikorg I, Lanzino G, et al. Pipeline for uncoilable or failed aneurysms: results from a multicenter clinical trial. Radiology 2013;267:858868

4. Lylyk P, Miranda C, Ceratto R, Ferrario A, Scrivano E, Luna HR, et al. Curative endovascular reconstruction of cerebral aneurysms with the pipeline embolization device: the Buenos Aires experience. Neurosurgery 2009;64:632-642

5. Nelson PK, Lylyk P, Szikora I, Wetzel SG, Wanke I, Fiorella D. The pipeline embolization device for the intracranial treatment of aneurysms trial. AJNR Am J Neuroradiol 2011;32:34-40

6. Kadirvel R, Ding YH, Dai D, Rezek I, Lewis DA, Kallmes DF. Cellular mechanisms of aneurysm occlusion after treatment with a flow diverter. Radiology 2014;270:394-399

7. Diaz O, Gist TL, Manjarez G, Orozco F, Almeida R. Treatment of 14 intracranial aneurysms with the FRED system. J Neurointerv Surg 2014;6:614-617

8. de Andrade GC, Alves HP, Clí maco V, Pereira E, Lesczynsky A, Frudit ME. Two-stage reconstructive overlapping stent LEO+ and SILK for treatment of intracranial circumferential fusiform aneurysms in the posterior circulation. Interv Neuroradiol 2016; 22:516-523 